\title{
AlpArray in Austria and Slovakia: technical realization, site description and noise characterization
}

\author{
Florian Fuchs $^{1}$, Petr Kolínský ${ }^{1}$, Gidera Gröschl ${ }^{1}$, Götz Bokelmann ${ }^{1}$, and the AlpArray Working Group* \\ ${ }^{1}$ Department of Meteorology and Geophysics, University of Vienna, Althanstraße 14, UZA 2, 1090 Vienna, Austria \\ * http://www.alparray.ethz.ch \\ Correspondence to: Florian Fuchs (florian.fuchs@univie.ac.at)
}

Received: 30 June 2016 - Revised: 7 September 2016 - Accepted: 23 September 2016 - Published: 7 October 2016

\begin{abstract}
We report the technical realization and performance of thirty temporary seismic broadband deployments for the AlpArray project in eastern Austria and western Slovakia. Reftek 151 60s sensors and Reftek 130/130S digitizers form the core instrumentation of our seismic stations; these are mostly installed inside abandoned or occasionally used basements or cellars in small buildings or huts. We describe our type of installation and briefly introduce the site conditions for each of the thirty installations. We present a probabilistic power spectral density analysis to assess the noise conditions at all sites and potential relations to the installation design.
\end{abstract}

\section{Introduction}

The seismic stations described in this manuscript are part of the international AlpArray temporary seismic network (www.alparray.ethz.ch). AlpArray is a unique European transnational research initiative: 45 research institutes from 18 countries join their expertise to advance our knowledge about the structure and evolution of the lithosphere beneath the entire Alpine area (Hetenyi et al., 2016). AlpArray will shed light on the detailed geological structure and geodynamical evolution of the Alps to answer outstanding questions, e.g. on slab geometry and subduction polarity under the Eastern Alps (Kissling, 2016). While the primary scope of AlpArray is fundamental research, the unique dataset will also improve our knowledge about near-surface geologic structures and help to assess the seismic hazard in the Alpine area. The scientific goals of the AlpArray seismic network are manifold and among others include e.g. Alpine geodynamics, crustal and mantle imaging, seismic anisotropy, as well as regional and local seismic activity. Hence, temporary seismic stations installed in the framework of AlpArray should be multi-purpose stations that perform reasonably well for frequencies from above to below the microseism peaks.

Here we describe the site selection criteria, technical realization and noise performance of thirty temporary seismic broadband stations operated by the Department of Meteorology and Geophysics, University of Vienna in the context of AlpArray in eastern Austria and western Slovakia (see Table 1 for a complete station list). Few of the stations were already described in more detail by Fuchs et al. (2015).

\section{Network layout, site selection and station design}

\subsection{Network layout}

The AlpArray temporary seismic network is designed to complement existing permanent seismic stations in the greater Alpine area in Europe. In Austria, the Austrian Central Institute for Meteorology and Geodynamics (ZAMG) currently operates 17 permanent broadband stations which contribute data to the AlpArray seismic network. In Slovakia, the Earth Science Institute at the Slovak Academy of Sciences operates 4 permanent seismic broadband stations within the bounds of the AlpArray network. The temporary broadband seismic stations installed in the context of AlpArray densify the permanent networks to achieve a uniform coverage with approximately $40 \mathrm{~km}$ inter-station spacing (see Fig. 1) over the greater Alpine area. Theoretical coordinates for all temporary AlpArray stations were computed by the AlpArray seismic network managers to obtain homogeneous coverage throughout the entire array and all stations must be installed within a $3 \mathrm{~km}$ radius (maximally $6 \mathrm{~km}$ if otherwise impossible) around these coordinates. This 


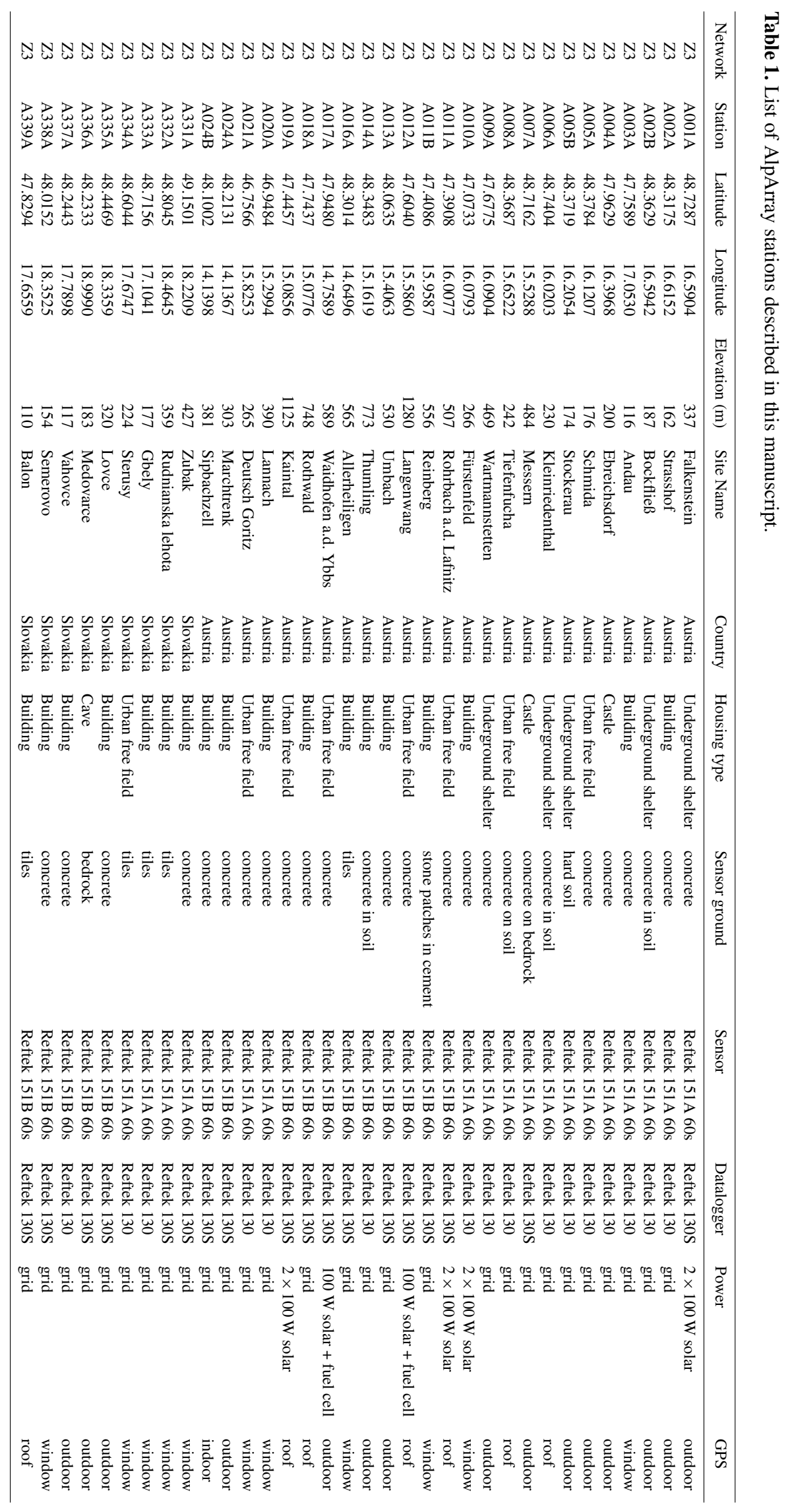




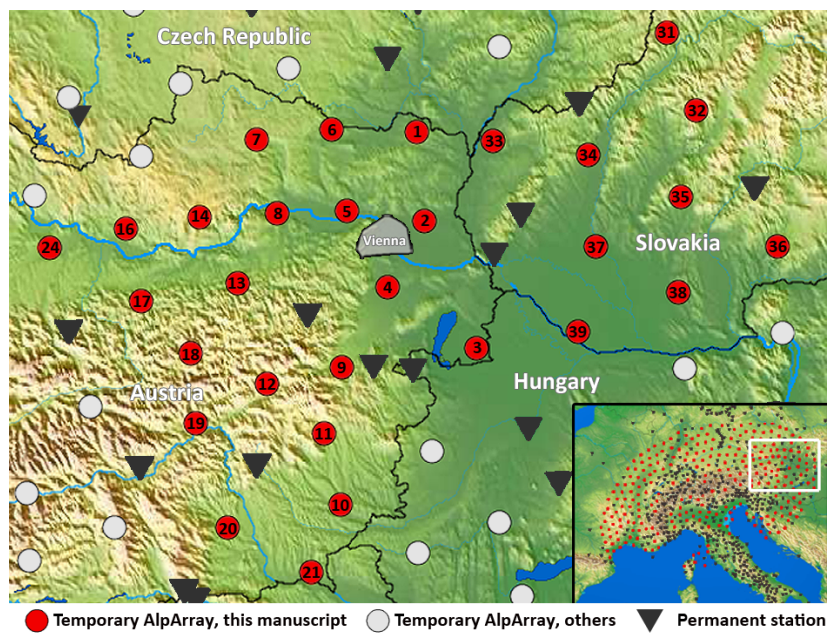

Figure 1. Map of seismic stations described in this manuscript. The inset outlines the mapped area. Red dots denote the 30 temporary AlpArray stations owned and operated by the Department of Meteorology and Geophysics, University of Vienna. White dots represent temporary AlpArray stations operated by other institutions. Black triangles mark the permanent seismic stations maintained by the earthquake observatories in Austria, Slovakia, Czech Republic and Hungary, respectively. The numbers inside the red dots abbreviate the station name in the following pattern: Austria stations = A0xxA, Slovakia stations $=\mathrm{A} 3 \times \mathrm{xA}$.

constraint strongly limits the choice of potential installation sites. The prospected duration of our temporary AlpArray installations is 2-3 years.

\subsubsection{Site selection}

During site selection for our temporary deployments we focused on the following aspects, taking into account both the quality of the seismic data as well as the ease of installation, reflecting the available project budget.

\section{Accessibility and safety}

All sites should be accessible by car and safe in terms of theft or flood risk and all parts of the station shall not be exposed to any risk of potential damage. Additionally, the terms and conditions of the instrument insurance require the seismic stations to be indoors in spaces that can be locked. The surroundings of the site should not significantly change over the course of three years (e.g. no ongoing or planned contruction).

\section{Power supply}

Most parts of Austria experience snow fall during winter and thus for many sites power supply through solar panels cannot be guaranteed. Hence, we prefer sites where power supply from the regular $50 \mathrm{~Hz} / 230 \mathrm{~V}$ power grid is possible.

\section{Connectivity}

For monitoring purposes and to provide real-time waveform data in case of hazardous earthquakes, all seismic stations should send real-time data using the mobile network. Minimum requirement is sufficient signal strength and stability to transmit state-of-health data, while preferably continuous 100 sps waveform streams should be transmitted. For our instrumentation and 100 sps waveform data in STEIM1 compression format, the amount of data to transmit is approximately 30 Megabytes day $^{-1}$ for seismically quiet sites and 50 Megabytes day $^{-1}$ for noisy sites. Thus, for 100 sps realtime waveform streams a mobile bandwidth of 5-10 kbits s ${ }^{-1}$ should be sufficient, which can even be achieved in GSM networks. In fact, stability of the mobile connection is more important than bandwidth.

\section{Seismic noise}

The AlpArray Working Group set the following requirements for temporary AlpArray stations: Average noise levels should be $20 \mathrm{~dB}$ lower than the New High Noise Model (NHNM) (Peterson, 1993) on all components within the $1-10 \mathrm{~Hz}$ frequency range. For long periods (30-200 s range) average noise levels on the vertical component should be $20 \mathrm{~dB}$ lower than the NHNM while on horizontal components noise levels should only be $10 \mathrm{~dB}$ less than the NHNM. This accounts for the strong sensitivity of horizontal components to e.g. longperiod surface tilt from atmospheric pressure fluctuations. This reflects the fact that for near-surface stations, noise on horizontal components is usually stronger than on the vertical. Avoiding long-period noise on horizontal components requires advanced site preparation (Forbinger, 2012) which is usually beyond the scope of temporary deployments.

\subsubsection{Station design}

Following the site requirements listed above, typical installation sites for our broadband instruments are basements in abandoned or occasionally used houses and huts. In various regions throughout Austria and Slovakia wine cellars and occasionally castles or bunkers could be found for seismic installations. We placed all sensors directly on solid ground preferably flat bedrock, but more commonly concrete floors or tiles. If no such ground was available, we built a concrete base approximately $15-20 \mathrm{~cm}$ thick and $60 \times 60 \mathrm{~cm}$ wide (see Fig. 2a). The sensors are covered with textile bags fabricated from microfleece material with primaloft insulation and styrofoam boxes for thermal insulation (see Fig. $2 b$ and c). To minimize air circulation we glue the bottom of the styrofoam boxes to the ground with silicon.

A seismic station comprises the following components: a broadband sensor Reftek 151 "Observer" with 60 s effective eigenperiod together with a Reftek 130 or Reftek 130S 24 bit digitizer with $>136 \mathrm{~dB}$ dynamic range (at 100 sps sampling 

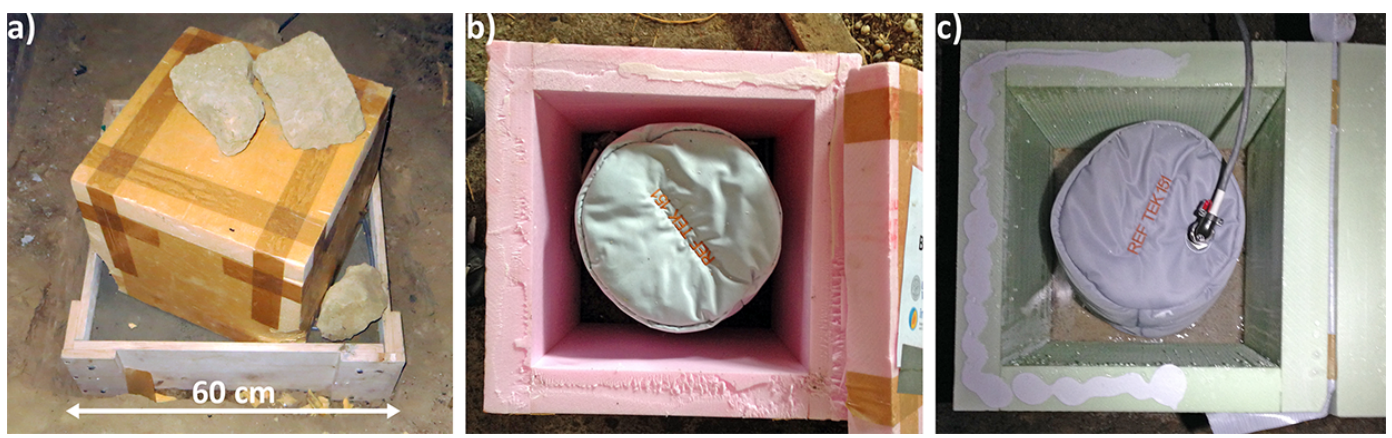

Figure 2. (a) Example of a concrete base if no solid ground is available (A006A). (b) and (c) Two-layer thermal insulation comprising a microfleece bag inside a styrofoam box. The box is glued to the ground with silicon. (b) Reftek 151 Type A sensor with connector at the bottom. (c) Reftek 151 Type B sensor with connector at the top.

rate), a continuous-mode Garmin/Reftek 130 GPS, a Digi WAN $3 \mathrm{G}$ mobile router for telemetry and up to two $100 \mathrm{Ah}$ batteries. Figure 3 shows the seismic equipment and Fig. 4 shows a typical installation. Data is both stored locally (on two 8 or $16 \mathrm{~GB}$ flash cards) and (if possible) streamed in realtime.

Currently, 24 of 30 stations are powered through the electrical grid, four stations are powered by two $100 \mathrm{~W}$ solar panels (see Fig. 5a) and two stations are powered by one $100 \mathrm{~W}$ panel and one Efoy Pro 800 Duo fuel cell. The fuel cell acts as backup power source when the batteries are drained below a given threshold, which is mostly due to insufficient illumination of the solar panel during the winter season. Solar charge controllers protect the batteries from overcharging and disconnect any load from the batteries if they are drained below $11.5 \mathrm{~V}$ to protect them from deep draining. If installed, the fuel cells are configured such that they start charging the batteries once the voltage drops below $12 \mathrm{~V}$.

The antennas for GPS timing and cellular communication were in part mounted outdoors and in part (14 of 30 stations) indoors close to windows or under wooden roofs (see Fig. 5b and c). Regarding the GPS indoor antenna installations we were woried about signal loss in case of snow, but studies on regular GPS receivers buried by snow covers document high quality GPS reception even for snow heights up to one meter (Stepanek and Claypool, 1997). Hence, for ease of installation and security we decided for the indoor installations in some cases. After approximately one year of data acquisition we cannot identify clear differences in the quality of the GPS signal between indoor and outdoor installations.

\subsubsection{Sensor orientation}

During the deployment, the sensor orientation along the (supposedly geometrical) North-South axis was determined with a magnetic compass, not accounting for the magnetic declination. If possible, the heading of the magnetic compass was compared inside and outside of the housing structure (e.g. by comparing the measured orientation of walls) and
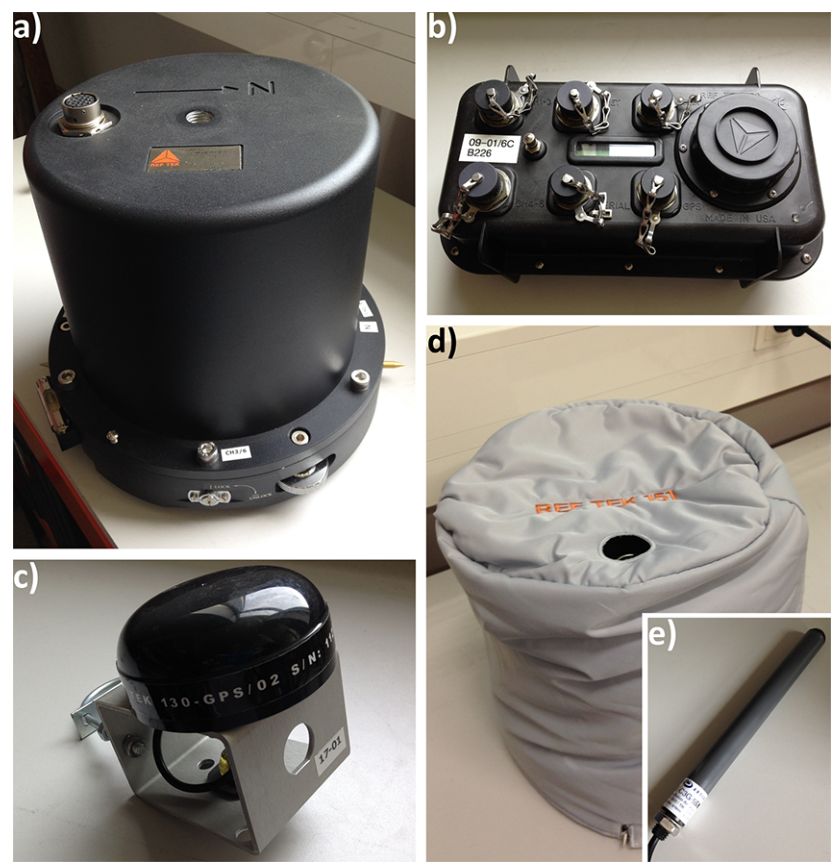

Figure 3. Equipment used for the installations described in this manuscript. (a) Reftek 151 60s sensor, ( Reftek 130/130S digitizer, (c) Reftek 130 GPS antenna, (d) Textile thermal insulation cover for the sensor, (e) Mobile network antenna.

manually corrected in case of strong differences. However, after the installation of all thirty stations we re-measured and checked the orientation of all sensors with a fiberoptic gyrocompass and discovered substantial deviations from true geometrical North for approximately one third (11 of 30) of the sensors. For those sensors, the Azimuth of the North-South component deviates more than $7^{\circ}$ from geometrical North. Following the SEED and AlpArray guidelines, for mis-oriented sensors we re-named the $\mathrm{N}$ and $\mathrm{E}$ channels to 2 and 3, respectively, to make data users aware of the mis-orientation. The correct sensor alignment for all stations is provided in the station metadata in datalessSEED 

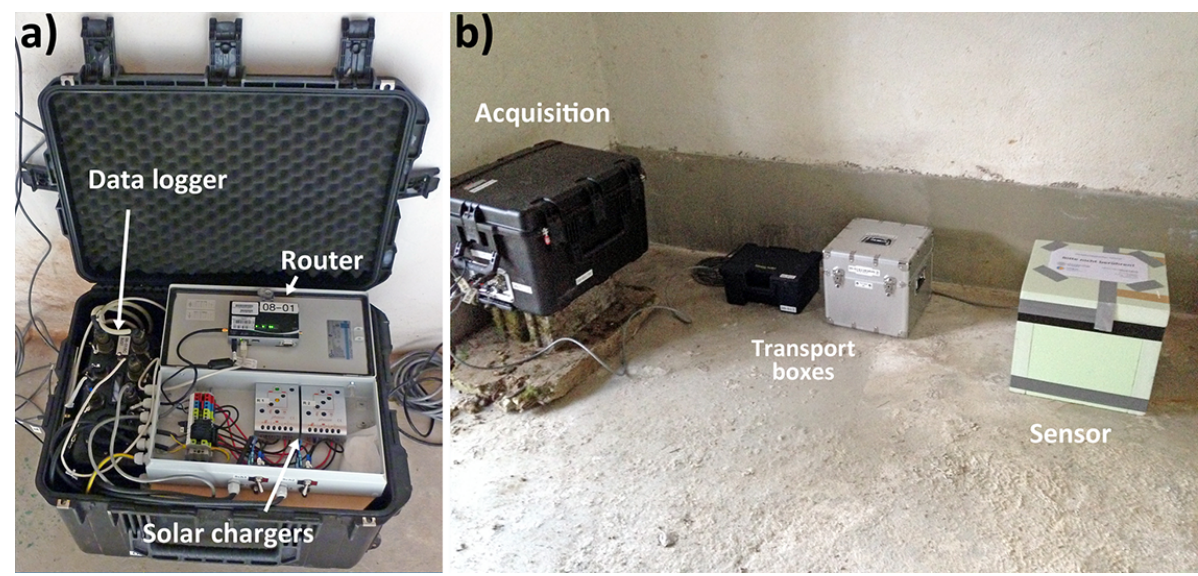

Figure 4. (a) Acquisition box containing the data logger Reftek 130/130S, the cellular router, the solar chargers and two 100 Ah batteries (not visible). (b) Typical setup of a seismic station as described in this manuscript (A017A).
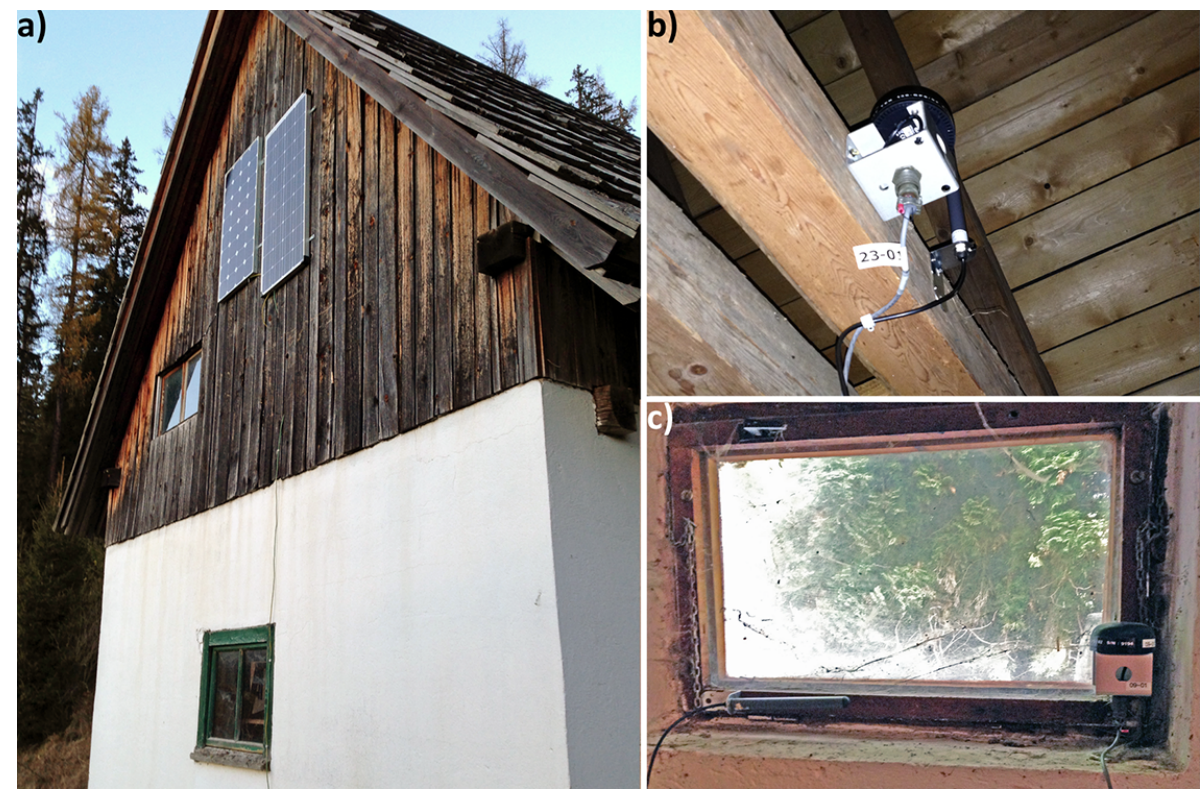

Figure 5. (a) Example of solar panel mounting (A019A). If required, two $100 \mathrm{~W}$ solar panels are mounted, usually vertically on walls or chimneys. (b) GPS and GSM antenna mounted indoors below wooden roof (A018A). (c) GPS and GSM antenna mounted indoors close to window (A331A).

format. Apart from metadata access through e.g. EIDA, the latest metadata of the 30 stations operated by University of Vienna is available at http://imgw.univie.ac.at/en/research/ geophysics/projects/aaa/instruments/.

\subsubsection{Data transmission and completeness}

All stations transmit 100 sps waveform streams and state of health data in real-time over the cellular network. Each station is equipped with a DIGI connect WAN $3 \mathrm{G}$ cellular router that automatically updates its current IP address via a dynamic DNS service to obtain a permanent domain name. Every five minutes our data retrieval server checks for and if necessary re-establishes a VPN connection with the cellular routers based on this dynamic DNS adress. This way the telemetry is not affected by changing mobile IP addresses in case of connection losses. Since in our setup the telemetry server is initiating the VPN connections with the mobile routers (because of very restrictive department firewall settings), all devices must be registered with public IP adresses, which is no longer common for mobile internet devices. Consequently, we registered all SIM cards for public IP addresses at the respective providers (A1 in Austria and Orange in Slovakia).

For data transmission we use the Reftek proprietary RTPD protocol which allows for real-time waveform and state 


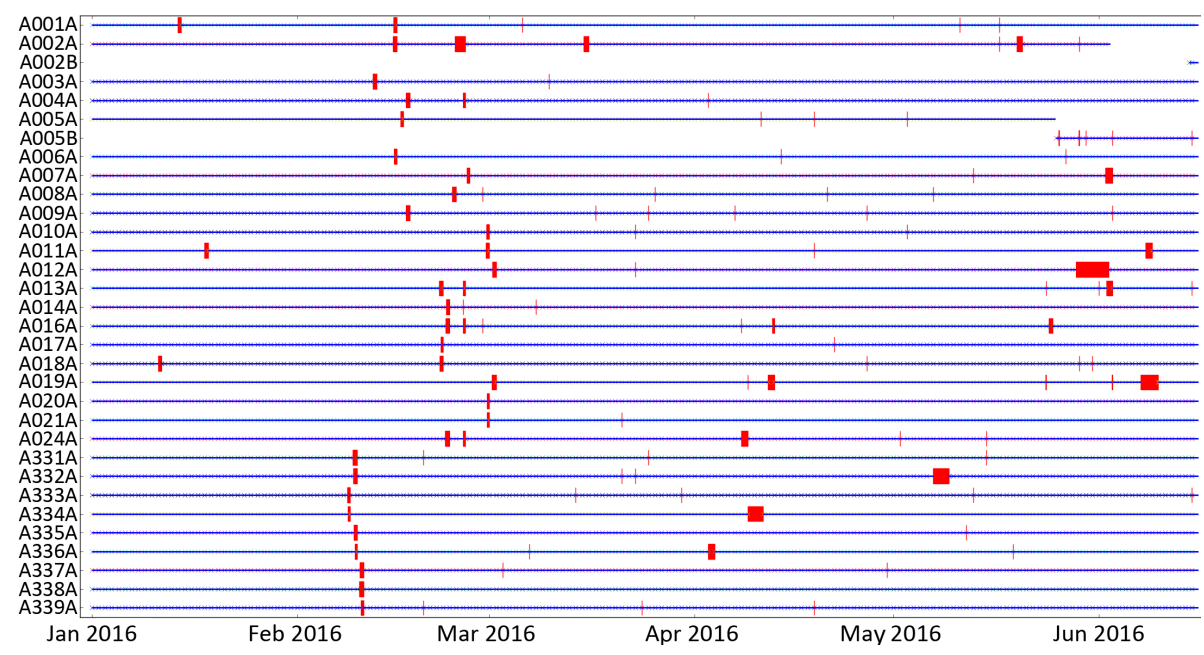

Figure 6. Completeness plot of 100 sps waveform data retrieved over telemetry. Small crosses mark start and end of the respective daily files and red lines/bars indicate data gaps. Data is from January to June 2016. The overall completeness is around $98 \%$.

of health monitoring. Real-time data is forwarded to the Austrian earthquake observatory (ZAMG) from where it is streamed to the Orfeus Data Center (ODC) for archiving and distribution through EIDA.

As stated above, even 5-10 $\mathrm{kbit} \mathrm{s}^{-1}$ of mobile bandwidth are sufficient for streaming 100 sps waveform data and hence we managed to have all 30 stations send 100 sps streams in real-time. Still, in some remote areas we occasionally experience loss of mobile signal and consequently a breakdown of telemetry. In case of a connection loss, our Reftek digitizers are configured such that they can keep recorded data in memory for up to $90 \mathrm{~min}$ before it is discarded and not streamed over telemetry. All data is stored locally on 16 or $32 \mathrm{~GB}$ flash cards in any case. Figure 6 visualizes the completeness of the $100 \mathrm{sps}$ waveform data streamed from our stations since January 2016. Averaged over all stations, between January and mid June 2016 we retrieved $98.6 \%$ of the data in real-time. Throughout the operation of our AlpArray stations, updated quarterly data completeness plots will be made available at http://imgw.univie.ac.at/en/research/geophysics/ projects/aaa/availability/.

\section{Site descriptions}

Our first temporary AlpArray station was installed in February 2015 (A009A) and we concluded the deployment in November 2015 (A010A). Few stations experienced power losses during the first winter months of 2015 because of insufficient solar power, but this was fixed (by adding a second solar panel or a fuel cell) before christmas 2015. Since January 2016 - which is the official AlpArray seismic network starting date - all of our 30 stations are fully operational. Four stations (A002A, A005A, A011A, A024A) have been moved to new sites in June 2016 because their noise levels were unacceptable (see below). They were replaced by stations A002B, A005B, A011B, A024B, respectively which perform much better than the previous site.

In the following we briefly describe each station in terms of sensor installation, ground type, housing characteristics and the geological setting. Station pictures and aerial views, as well as noise plots of all stations are available in the online material. Please note that stations pictures, aerial and map views, as well as sensor housing and geological descriptions for all stations are also available online at the European Station Book hosted by the ODC: http://www.orfeus-eu.org/ opencms/stationbook/index.html. Table 1 contains a comprehensive list of the stations, including instrumentation and coordinates.

- A001A is located inside a small abandoned WW2 bunker, that is built on a limestone formation within a gentle hillside. The sensor is put directly onto the bunker concrete floor in a corner furthest from any window or entry. The site is surrounded by vineyards and lies $700 \mathrm{~m}$ outside a small village and $300 \mathrm{~m}$ from the nearest road. This station shows the second lowest (best) noise levels of all stations. A001A is powered by two $100 \mathrm{~W}$ solar panels.

- A002A was placed inside the basement of an abandoned workers residential building ( 3 floors, $30 \times 10 \mathrm{~m}$ ). The sensor was put on the screed floor. The site is located in the flat part of the Vienna basin with the geology dominated by soft sand-like sediments. It was $300 \mathrm{~m}$ from a village, $300 \mathrm{~m}$ from busy railways and next to a mining road which was heavily used by trucks. This station was replaced by A002B because it did not meet the noise requirements and was unsafe.

- A002B replaced A002A. The station is installed inside an abandoned wine cellar, approximately $10 \mathrm{~m}$ below 
the free surface and $20 \mathrm{~m}$ from the entrance. The sensor is placed on a concrete base filled into a hole approximately $60 \mathrm{~cm}$ deep. The styrofoam box is buried by the soft fine grained sand/clay sediments which form the dominant geology around. The site is located at the foot of a narrow chain of hills and at the edge of a small village and $700 \mathrm{~m}$ from an oil field in production. The site shows elevated high frequency noise levels (similar to A002A) but satisfying long period performance.

- A003A is placed on surface level inside a barely used farm storage building ( 1 floor, $100 \times 10 \mathrm{~m}$ ). The sensor is placed on a small patch of concrete attached to one of the inside walls. Geologically the site is part of the flat Little Hungarian plain, which is part of the Pannonian basin. This station is $4 \mathrm{~km}$ from a wind turbine park (38 turbines, $114 \mathrm{MW}$ ). The noise spectrum shows anomalous high frequency noise peaks and strong horizontal long period variation.

- A004A is installed in the basement of an inhabited castle (4-5 floors, $50 \times 50 \mathrm{~m}$ ) which is located inside a village. The site is located inside the flat part of the Vienna basin and dominated by sediments. Consequently this station shows elevated noise levels.

- A005A was located inside a small village, sheltered by a brick hut $(2 \times 2 \mathrm{~m})$. The sensor was put on the concrete floor at ground level. The station suffered from strong anthropogenic and long period noise. This station was replaced by A005B because it did not meet the noise requirements.

- A005B replaced A005A because it did not meet the noise requirements. The sensor is installed inside an unused underground storage cellar on rather solid ground, which is however not rock. The site is part of the Danube flood plain and thus dominated by river sediments. Regarding the site conditions, noise levels are satisfactory. High frequency noise ranges between the NHNM and the $-20 \mathrm{~dB}$ requirement, but the long period noise levels are met.

- A006A is inside an abandoned wine cellar, approximately $4 \mathrm{~m}$ below the free surface. The sensor is placed on a concrete base built into hardened soil ground of Loess type geology of hillside morphology. The site is $200 \mathrm{~m}$ outside a small village and $300 \mathrm{~m}$ from a road. Despite the underground installation this site suffers from rather high short and long period noise.

- A007A is located in the basement of the entrance building ( 1 floor, $15 \times 10 \mathrm{~m}$ ) of an occasionally inhabited castle. The sensor is put on the screed floor, which has direct contact to the host rock. Few residential houses are near the castle, but still this site shows the best noise levels of all stations.
- A008A is sheltered by a small wooden hut $(2 \times 2 \mathrm{~m})$ and the sensor is put onto a big concrete base built into the foundation of the hut (on ground level). The site lies inside a small depression and is close to a flooding protection facility $200 \mathrm{~m}$ outside a small village. The surrounding vineyard hillside is dominated by clay and sedimentary geology. Despite the rather exposed surface installation the station meets all noise requirements.

- A009A is placed at the end of an underground storage built $3 \mathrm{~m}$ into a hill slope and approximately $2 \mathrm{~m}$ below the surface. The sensor is put onto the concrete floor. Above the storage cellar there is a wooden hut $(3 \times 4 \mathrm{~m})$ hosting a small telescope for private use. The site is next to a stand-alone residential house but $600 \mathrm{~m}$ from the next settlement. This station satisfies all noise requirements.

- A010A is installed in the basement of an unfinished residential house ( 1 floor, $9 \times 20 \mathrm{~m}$ ). The sensor is put on the concrete (or screed) floor. The site locates in flat silttype geology and is $1 \mathrm{~km}$ from a town and $500 \mathrm{~m}$ from a busy road. High frequency noise levels are elevated during daytime but otherwise the noise levels are satisfactory. The station is powered by two $100 \mathrm{~W}$ solar panels.

- A011A is on ground floor inside a partly derelict house ( 1 floor, $6 \times 6 \mathrm{~m}$ ) in the forest. The local geology is of silt type and the morphology is hillside. The site is $400 \mathrm{~m}$ from a busy road and $800 \mathrm{~m}$ from industrial facilities. Noise levels were rather high and this station was relocated in June 2016.

- A011B replaced A011A and is installed on a hill inside a small and rarely used chapel $(20 \times 8 \mathrm{~m})$. The local geology is of silt type and the morphology is hillside. The chapel is $50 \mathrm{~m}$ from a small settlement and $300 \mathrm{~m}$ from a road. All noise requirements are met.

- A012A is located inside a wooden mountain hut (1 floor, $5 \times 10 \mathrm{~m}$ ) that is built into a rather steep hill slope and surrounded only by forest $(4 \mathrm{~km}$ from the nearest village), inaccessible to the public. The sensor is put onto the concrete foundation (on ground level) which reaches into the hut at the chimney. Because of the remote location, high frequency noise is low, as expected, but the station suffers from rather strong and strongly varying long period noise. This station is powered by one $100 \mathrm{~W}$ solar panel and a fuel cell, which is approximately $3 \mathrm{~m}$ from the sensor.

- A013A is placed in the basement of an abandoned farm building ( 2 floors, $35 \times 25 \mathrm{~m}$ ). The sensor is put on the screed/concrete floor. The site is located inside steep to gentle hillside. A neighboring farm is $150 \mathrm{~m}$ far and the 
site is $50 \mathrm{~m}$ from a road but otherwise there is little surrounding population. Expect for strongly varying horizontal long period noise the site shows good noise levels.

- A014A is installed in the basement of an uninhabited farm house which is used for storage ( 2 floors, $30 \times 30 \mathrm{~m}$ ). The sensor is placed on a concrete base which is built into clay. The site locates on a slope in hillside terrain. Few inhabited houses surround the station and it is $400 \mathrm{~m}$ from a sawmill and a busy road. Except for the East component, where noise is $10-20 \mathrm{~dB}$ higher than on the North component, this station meets all noise requirements.

- A016A is inside a community fire house (2 floors, $10 \times 20 \mathrm{~m}$ ). The sensor is placed on tiles on ground floor level close to the outside walls. The site is located on top of a ridge in hillside terrain, surrounded by several residential and community buildings and $70 \mathrm{~m}$ from a road. Despite the location inside a settlement high frequency noise levels are low. However, horizontal long period noise is strong and strongly varying.

- A017A is sheltered by a small abandoned brick/concrete hut built into a steep slope $(6 \times 4 \mathrm{~m})$. The site locates on a very steep boundary flank of a hill formation (200 m elevation with respect to valley level) and $600 \mathrm{~m}$ from the outskirts of a village. The sensor is placed onto the screed/concrete floor (see Fig. 4). Noise levels are good except for strong and strongly varying horizontal long period noise. The station is powered by one $100 \mathrm{~W}$ solar panel and a fuel cell which is $5 \mathrm{~m}$ from the sensor.

- A018A is located inside a wooden house (1 floor, $18 \times 8 \mathrm{~m}$ ) which is used for storage. The sensor (on ground level) is put on the concrete foundation of the house, close to an outside wall. The site lies inside a river valley, on top of ancient river terraces. The station is $150 \mathrm{~m}$ from a river and neighbored by 4 similar uninhabited houses but otherwise far from any settlements. Although the station is affected by varying horizontal long period noise it mostly meets even the horizontal noise requirements.

- A019A is installed on ground level inside a hut $(7 \times 5 \mathrm{~m})$ which is close to a bigger wooden holiday house. The sensor is placed on the concrete/screed ground close to the barely isolating outside walls. The site locates on a steep slope in mountain terrain. It is $700 \mathrm{~m}$ from a quarry of unknown activity but otherwise far from any settlements. Noise levels are low except strong horizontal long period noise. The station is powered by two $100 \mathrm{~W}$ solar panels.
- A020A is placed at ground level inside an unused barn and agricultural storage building $(30 \times 23 \mathrm{~m})$ close to one inhabited house. The sensor is placed onto the concrete floor, close to an outside wall. The site is located inside hillside with scattered residential houses. The closest neighboring house is $150 \mathrm{~m}$ far and a village with industry is $2.5 \mathrm{~km}$ far. The station fulfills the high frequency requirements during quite times and show varying horizontal long period noise.

- A021A is located on the edge of a cemetery and sheltered by a small brick hut $(5 \times 5 \mathrm{~m})$ used for storage. The sensor is placed on the concrete/screed floor. The site situates in flat hillside dominated by clays. There is a residential building $50 \mathrm{~m}$ from the hut and it is $250 \mathrm{~m}$ to a village and a road. High frequency noise limits are met at night and long period noise is mainly within the noise requirements.

- A024A is installed in an unused room in the basement of an inhabited farm house $(65 \times 40 \mathrm{~m})$. The sensor is placed on the concrete floor. The site locates inside a flat Molasse type geology. The farm is surrounded by agriculture and in between two railways, 200 and $350 \mathrm{~m}$ far, respectively. The site exceeds the high frequency noise limits but performs well on all components in the long period range. Since railtraffic was too busy, this station was relocated in August 2016.

- A024B replaced A024A and is placed in a $2 \mathrm{~m}$ deep pit inside an inhabited farm building ( 2 floors, $70 \times 40 \mathrm{~m}$ ). The sensor is located in an unused part of the house, with no regular activity. The surrounding morphology is hillside shaped by ancient glacial deposits (conglomerate). The farm is surrounded by fields and agriculture but otherwise far from any bigger settlement or road. First noise spectra show good long period performance and high frequency noise between 10 and $20 \mathrm{~dB}$ less than the NHNM.

- A331A is located in a cellar of a cemetery house $(10 \times 6 \mathrm{~m})$, slightly under surface level in a hill. The sensor is placed on the concrete floor. The site lies inside sandstone dominated hillside and is just on the edge of a small village. This site meets all noise requirements.

- A332A is installed at surface level of a large cemetery house $(20 \times 13 \mathrm{~m})$ that contains a church tower with a bell ringing four times a day. The sensor is placed on the tiles of a rarely visited cleaning storage room. The site is surrounded by hilly landscape created by alluvial deposits. Noise limits are kept except for horizontal long periods, which are strong and strongly varying.

- A333A is placed in the cellar of rarely used distillery house $(28 \times 24 \mathrm{~m})$. The sensor is put on the concrete 


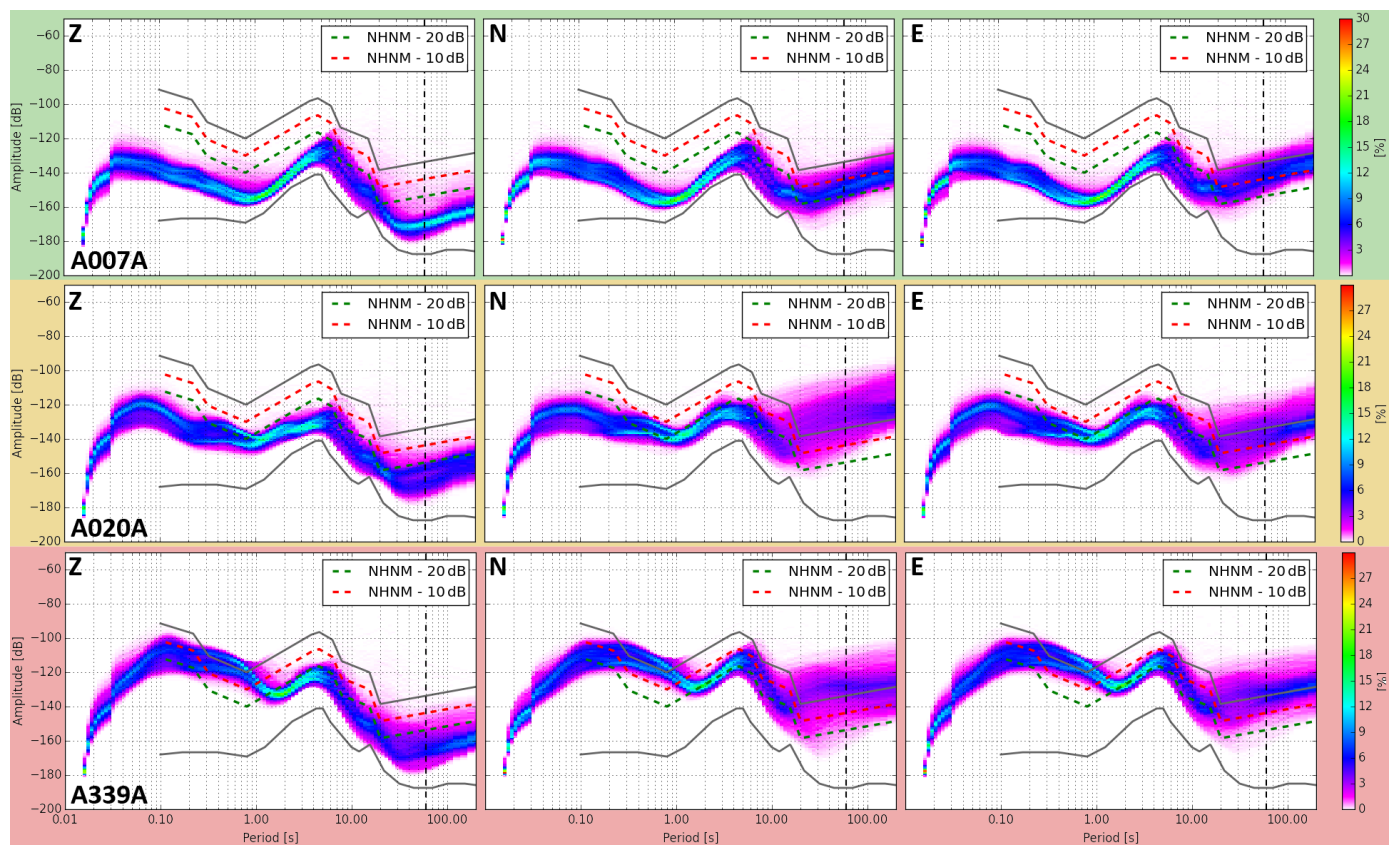

Figure 7. Examples of probabilistic power spectral densities for the three quality groups. First row (green): Example of a station (A007A) which meets the noise requirements at all times on all components. Middle row (orange): Example of a station (A020A) which partly meets the noise limits on some components and shows strong variation in long period horizontal noise. Bottom row (red): Example for a station (A339A) which on most components exceeds the noise limits. Solid lines mark the NHNM and NLNM noise models (Peterson, 1993). Dashed lines mark the NHNM-20 and -10 dB noise limits, respectively, and the vertical line at 60 s period marks the corner frequency of our instruments. All graphs were calculated for the timespan January-May 2016. Please find individual graphs for all stations in the Supplement.

floor. The site lies within plain sand like sediments near the borders of a small town. The site suffers from elevated high frequency noise and only for some times can fulfill the long period requirements on the horizontal components.

- A334A is put at the ground level in a small cemetery house $(10 \times 7 \mathrm{~m})$. The sensor is placed onto the tile floor. The site is inside hillside of Loess type geology and lies at the edge of a small village. There is a quarry at $2.5 \mathrm{~km}$ distance. The noise spectrum of this station is affected by few artificial peaks in both high and low frequencies and rather strong horizontal long period noise. Consequently this stations meets the noise requirements only during quiet times for some of the components.

- A335A is installed $2 \mathrm{~m}$ under the surface level in a pit inside an unused electric controlling house $(6 \times 6 \mathrm{~m})$. The sensor is placed onto the concrete ground. The site is at a tree nursery in the middle of a large forest and $1.5 \mathrm{~km}$ from the closest populated area. High frequency noise is acceptable but long period noise varies strongly on all components.

- A336A is approximately $10 \mathrm{~m}$ under the surface in a wine cellar $10 \mathrm{~m}$ from the entrance. The sensor is placed directly on the hard volcanic type rock. The site lies at the edge of a small village, $100 \mathrm{~m}$ from a road and $50 \mathrm{~m}$ from a river. High frequency noise is within the limits but horizontal long period noise partly exceeds the limits. Notably here is a substantial difference in noise levels among the two horizontal components, one of which (component 3/supposedly E) shows strong separation into two noise branches (see the Supplement).

- A337A is installed $2 \mathrm{~m}$ under the surface level in a big unused agricultural storage house $(40 \times 13 \mathrm{~m})$. The sensor is placed at the concrete floor. The station is situated in the sedimentary plain of a river, at the edge of a village and $800 \mathrm{~m}$ from a dammed river reservoir. Except for vertical long period all noise limits are exceeded.

- A338A is located at the ground level in a cemetery house $(15 \times 15 \mathrm{~m})$. The sensor is installed on the concrete floor. The site lies inside clay dominated hillside and just outside a small village. Noise requirements are partly met for high frequencies but horizontal long period noise is strongly varying.

- A339A is placed $2 \mathrm{~m}$ under the surface level in a cellar of an unused storage building $(25 \times 5 \mathrm{~m})$ of an operating chicken farm. The sensor is placed onto a tile floor. The site lies within the all flat danube flood plain $3 \mathrm{~km}$ from 


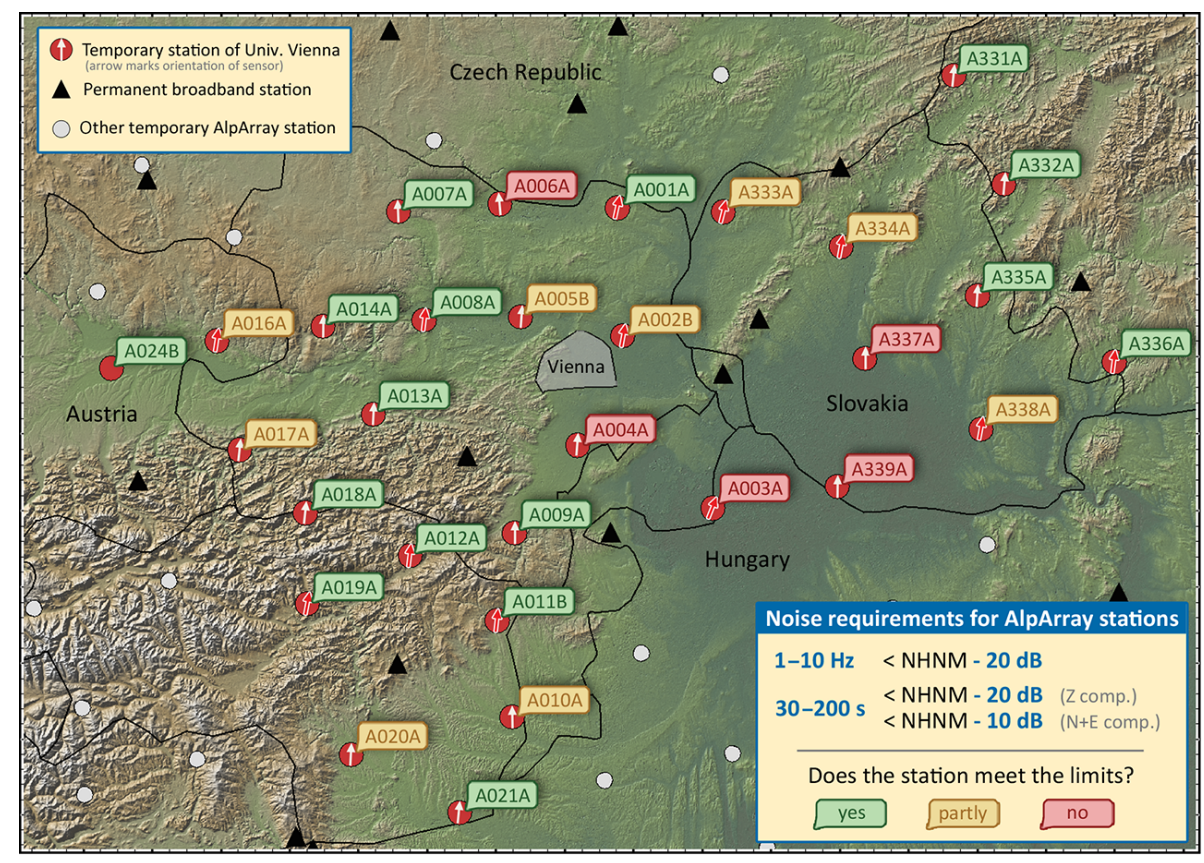

Figure 8. Map visualizing which stations meet the noise requirements. Color coding follows the listing in Table 2. The evaluation of the noise levels is based on five months of data from January-May 2016 (except for the B stations, which were judged from first data in June/August). The arrows inside the red dots indicate the true orientation of the sensor. Thick arrows denote sensors within $\pm 5^{\circ}$ deviation from geometrical North (and channels named HHN, HHE) while outlined arrows mark sensors with a greater deviation from true North (and channels named $\mathrm{HH} 2, \mathrm{HH} 3$ ). For station A024B, the correct orientation was not checked with a gyrocompass, yet.

the danube and $800 \mathrm{~m}$ from a village. Long period vertical noise limits are met, but all other noise requirements are strongly exceeded.

\section{Noise performance}

We classify the noise performance of our stations into three groups, according to the noise requirements set by the AlpArray Working Group. Stations that fulfill the noise requirements (see Sect. 2) in both frequency ranges $(1-20 \mathrm{~Hz}$ and 30-200 s) for most of the components at all times fall into group green. If only some components (e.g. the vertical) meet the required noise levels for some of the frequency ranges or if there is strong temporal variation (e.g. anthropogenic noise with day/night cycle) in the noise levels, the station falls into group orange. Group red contains stations which do not meet the noise requirements for most of the components in both frequency ranges. Figure 7 shows examples of probabilistic power spectral density plots for each group and Fig. 8 visualizes which stations meet the noise requirement and which don not. Table 2 summarizes the noise performance of all 30 stations by the individual components. Individual power spectral density graphs (calculated from five months of data, January-May 2016) are available in the online material. Updated monthly power spectral density plots for our AlpArray stations are available at http://imgw.univie.ac.at/en/research/ geophysics/projects/aaa/ppsd/. All probabilistic power spec- tral density graphs were created with the ObsPy toolbox (Krischer et al., 2015) following the procedure of McNamara and Buland (2004).

To summarize, in the high frequency range $(1-20 \mathrm{~Hz}) 50 \%$ of our stations are at least $20 \mathrm{~dB}$ below the NHNM on both vertical and horizontal components. $25 \%$ of the stations meet the limits during quiet times (i.e. at night) and another $25 \%$ are affected by strong high frequency noise and cannot fulfill the noise requirements. The latter stations are almost exclusively located in sedimentary basins and/or close to anthropogenic noise sources.

In the long period range (30-200s) noise performance clearly separates into vertical and horizontal components. On the vertical component all stations show noise levels of $20 \mathrm{~dB}$ below the NHNM or better and thus meet the AlpArray noise requirements. However, many stations are affected by rather strong horizontal long period noise. For most of the stations, horizontal noise is up to several tens of $\mathrm{dB}$ higher than the vertical noise level. Still, $30 \%$ of the stations satisfy the requirements on the horizontal components, but another $30 \%$ experience noise levels in the range of the NHNM or higher. $40 \%$ of the stations show strong variations in horizontal noise (see orange example, A020A in Fig. 7) and only during unspecifiable quiet times meet the noise requirements.

We cannot relate the susceptibility of a station to long period horizontal noise to a specific housing type. Among the well performing stations are those in well-isolated under- 
Table 2. This table summarizes the noise performance of all stations by components. Green fields indicate that the noise limits are met, orange fields denote that the noise requirement are partly exceeded and red fields mark components which do not satisfy the noise requirements. The color of the station name relates to the coloring in Fig. 8 and judges the overall noise performance of any given station. The stations with grey italic text (A002A, A005A, A011A, A024A) have been removed and replaced by respective stations with B as last letter. The evaluation of the noise levels is based on five months of data from January-May 2016 (except for the B stations, which were judged from first data in June/August).

\begin{tabular}{|c|c|c|c|c|c|c|}
\hline \multicolumn{4}{|c|}{ High (1-10 Hz) } & \multicolumn{3}{|c|}{ Low (30-200 s) } \\
\hline & Z & $\mathrm{N} / 2$ & $E / 3$ & Z & $\mathrm{N} / 2$ & $E / 3$ \\
\hline $\mathrm{A} 001 \mathrm{~A}$ & yes & yes & yes & yes & yes & yes \\
\hline$A 002 A$ & no & no & no & partly & partly & partly \\
\hline $\mathrm{A} 002 \mathrm{~B}$ & no & no & no & yes & yes & yes \\
\hline A003A & no & no & no & yes & partly & no \\
\hline A004A & no & no & no & yes & no & no \\
\hline A005A & no & no & no & no & no & no \\
\hline A005B & partly & partly & partly & yes & partly & partly \\
\hline A006A & partly & no & no & yes & no & no \\
\hline A007A & yes & yes & yes & yes & yes & yes \\
\hline A008A & yes & partly & partly & yes & yes & yes \\
\hline A009A & yes & yes & yes & yes & yes & yes \\
\hline A010A & partly & partly & partly & yes & yes & yes \\
\hline$A 011 A$ & partly & no & no & yes & no & no \\
\hline A011B & yes & yes & yes & yes & partly & partly \\
\hline $\mathrm{A} 012 \mathrm{~A}$ & yes & yes & yes & yes & no & no \\
\hline A013A & yes & yes & yes & yes & partly & partly \\
\hline $\mathrm{A} 014 \mathrm{~A}$ & yes & yes & yes & yes & yes & no \\
\hline A016A & yes & yes & yes & partly & no & no \\
\hline$A 017 A$ & yes & yes & yes & yes & partly & no \\
\hline A018A & yes & yes & yes & yes & yes & yes \\
\hline A019A & yes & yes & yes & yes & partly & partly \\
\hline $\mathrm{A} 020 \mathrm{~A}$ & yes & partly & yes & yes & no & partly \\
\hline $\mathrm{A} 021 \mathrm{~A}$ & yes & partly & partly & yes & yes & yes \\
\hline$A 024 A$ & no & no & no & yes & yes & yes \\
\hline$A 024 B$ & yes & partly & partly & yes & yes & yes \\
\hline $\mathrm{A} 331 \mathrm{~A}$ & yes & yes & yes & yes & yes & yes \\
\hline A332A & yes & yes & yes & yes & partly & partly \\
\hline A333A & no & no & no & yes & partly & partly \\
\hline A334A & partly & partly & partly & yes & partly & no \\
\hline A335A & yes & yes & yes & yes & partly & partly \\
\hline A336A & yes & yes & yes & yes & partly & partly \\
\hline$A 337 A$ & no & no & no & yes & no & partly \\
\hline A338A & partly & partly & partly & yes & partly & partly \\
\hline A339A & no & no & no & yes & no & partly \\
\hline
\end{tabular}

ground shelters as well as surface stations inside big or small aperture buildings or huts. Similarly there is no clear relation between sensor shelter and strong or strongly varying long period noise. We do note, however, that for the majority of stations vertical noise levels are much lower (up to several tens of $\mathrm{dB}$ ) than horizontal noise levels. Additionally, for some sites we observe up to $20 \mathrm{~dB}$ difference in noise levels between the two horizontal components. This may reflect local site conditions or effects which should be studied further. Since our stations are not pressure sealed or installed on rigid baseplates they might be affected by pressure variations and long period surface tilt (Bormann and Wielandt, 2012; Forbinger, 2012). The latter may in particular cause the elevated horizontal noise levels (compared to vertical) on our stations since almost all of them are surface or near surface installations. Additionally, most stations are located inside 1-2 floors buildings which may pick up e.g. wind or temperature variations and thus create additional long period noise. However, even some of the well-performing sensors are located on surface level inside buildings. Convection in the surroundings of the sensor seems unlikely to be a dominant long period noise source since even some basement stations with almost constant temperature are affected. Convection inside the styrofoam box should be minimal due to the silicon sealing and little free space between the textile cover of the sensor and the styrofoam insulation box (see Fig. 2).

Gerner and Bokelmann (2013) determined the vertical self-noise of our Reftek 151 60s A generation sensors. They show self-noise levels below the NLNM for the flat part of the instrument velocity response down to the specified effective eigenperiod of $60 \mathrm{~s}$. At $200 \mathrm{~s}$ the sensor self-noise is $15 \mathrm{~dB}$ higher than at $60 \mathrm{~s}$ and exceeding the NLNM model. During personal communication they report occasional sequences of instability for generation A sensors with elevated 
self-noise levels for periods longer than the effective sensor eigenperiod. Still, the measured self-noise for the Reftek 151 60s A sensors for periods between 60 and $200 \mathrm{~s}$ is well below the horizontal long period noise levels we encounter in our deployments. Additionally, for stations affected by strong horizontal long period noise, the noise levels are elevated for all periods below 10s and the stations in question are equipped with both Reftek 151 A and B sensor generations. Hence, we conclude that the horizontal long period noise levels are not due to exceeding the sensor specified frequency range but rather due to housing and surface effects.

The majority of our stations is installed within sedimentary surface layers of unknown thickness and only few stations have direct contact to host rock. Wolin et al. (2015) point out significant diurnal variation in horizontal long period noise for shallow temporary vault installations inside thick layers of soft sediments. They relate the noise variations to the soil responding mainly to atmospheric pressure variations. We did not perform a detailed study of potential diurnal variations in noise levels for our stations, yet, but the strong variability seen in some of the probabilistic power spectral densities (calculated for 5 months, winter to spring) may reflect a similar effect. Aderhold et al. (2015) report similar variations for long period horizontal noise and suggest that for for sites in sedimentary geologies direct burial of broadband sensors may be favorable over vault emplacement.

\section{Conclusions}

The Department of Meteorology and Geophysics of the University of Vienna started deploying temporary broadband stations for the AlpArray project in early 2015. Since January 2016 thirty seismic stations equipped with Reftek 151 60s sensors and Reftek 130(S) data loggers are fully operational and sending 100 sps waveform streams to the ODC in realtime, using the cellular network. Since January 2016 we retrieve almost $99 \%$ of the data in real-time. Our stations follow a low-cost installation design and are usually placed inside basements of uninhabited houses, huts, cellars or castles. The sensor, insulated with a microfleece bag and a styrofoam box, is commonly put on concrete ground or tiles and in few cases on top of a constructed concrete base in soil. Most stations are powered through the power grid, while few stations feature a $2 \times 100 \mathrm{~W}$ solar panels installation or one $100 \mathrm{~W}$ panel and a fuel cell.

With such design $50 \%$ of the stations show highfrequency $(1-20 \mathrm{~Hz})$ noise levels which are $20 \mathrm{~dB}$ below the NHNM or less on all components. Another $30 \%$ reach the NHNM - $20 \mathrm{~dB}$ noise performance during quiet times (i.e. at night). All stations perform well for vertical long period (30-200 s) signals with noise levels $20 \mathrm{~dB}$ below the NHNM or less. However, horizontal long period noise levels are generally much stronger than the verticals and only $30 \%$ of our stations meet the NHNM $-10 \mathrm{~dB}$ requirements for horizon- tal long period noise. $40 \%$ of the stations are affected by strongly varying long period horizontal noise. This is likely due to the fact that all stations are surface or near surface stations inside or near the footprint of an artificial structure such as a building. Hence, our stations are affected by long period surface tilt introduced by e.g. atmospheric pressure variations and little or no efforts to minimize such effects were made for these temporary deployments.

Overall our low-cost deployment provides reliable and continuous seismic data of good quality in real-time and forms one integral part of the greater AlpArray seismic instrumentation. In particular, data from our stations will help to resolve outstanding questions and debates about the geological structures under the Eastern Alps, which is one of the key scientific targets of AlpArray.

\section{Data availability}

Seismic data used for this manuscript is currently not publicly accessible by decision of the AlpArray Working Group. Currently, all waveform data is exclusively available to registered members of the core group of the AlpArray seismic network. Please visit http://www.alparray.ethz.ch/seismic network/backbone/data-access/ for further information on data access.

\section{The Supplement related to this article is available online at doi:10.5194/adgeo-4-1-2016-supplement.}

Author contributions. F. Fuchs prepared the manuscript with contributions from all co-authors, coordinated the station deployments and manages data flow and quality control. P. Kolinsky and G. Gröschl scouted and deployed the majority of the seismic stations. G. Bokelmann is the principal investigator of AlpArray Austria and supervises the project. The AlpArray Working Group worked out the network layout, quality guidelines and standards for the seismic data exchange.

Acknowledgements. AlpArray Austria is funded by the FWF Austrian Science Fund project number P26391. We acknowledge planning and organization of the AlpArray coordinators Edi Kissling, György Hetenyi, Irene Molinari and John Clinton at ETH Zürich, Switzerland, who created the AlpArray seismic network layout. We gratefully acknowledge support of the Institute of Geophysics of the Czech Academy of Sciences for providing the fibreoptic gyrocompass. We thank Johann Huber for technical assistance and Maria-Theresia Apoloner for software assistance and help in the field. Herta Gassner is thanked for her administrational help. Felix Schneider, Ehsan Qorbani, Sven Schippkus and Eric Löberich are thanked for their help in the field. We thank all involved Austrian and Slovakian communities, forest 
administrations and individuals for their help during site scouting. We acknowledge help of the Slovak Academy of Sciences for operating the telemetry in Slovakia. We thank Aladino Govoni and one anonymous reviewer for their suggestions to improve the manuscript.

Edited by: D. Pesaresi

Reviewed by: A. Govoni and one anonymous referee

\section{References}

Aderhold, K., Anderson, K. E., Reusch, A. M., Pfeifer, M. C., Aster, R. C., and Parker, T.: Data Quality of Collocated Portable Broadband Seismometers Using Direct Burial and Vault Emplacement, B. Seismol. Soc. Am., 105, 2420-2432, doi:10.1785/0120140352, 2015.

Bormann, P. and Wielandt, E.: Seismic Signals and Noise, in: New Manual of Seismological Observatory Practice 2 (NMSOP2), edited by: Bormann, P., 1-62, Deutsches GeoForschungsZentrum GFZ, Potsdam, doi:10.2312/GFZ.NMSOP-2_ch4, 2012.

Forbinger, T.: Recommendations for seismometer deployment and shielding, in: New Manual of Seismological Observatory Practice 2 (NMSOP-2), edited by: Bormann, P., 1-10, Deutsches GeoForschungsZentrum GFZ, Potsdam, doi:10.2312/GFZ.NMSOP-2_IS_5.4, 2012.

Fuchs, F., Kolínský, P., Gröschl, G., Apoloner, M.-T., Qorbani, E., Schneider, F., and Bokelmann, G.: Site selection for a countrywide temporary network in Austria: noise analysis and preliminary performance, Adv. Geosci., 41, 25-33, doi:10.5194/adgeo41-25-2015, 2015.
Gerner, A. and Bokelmann, G.: Instrument self-noise and sensor misalignment, Adv. Geosci., 36, 17-20, doi:10.5194/adgeo-3617-2013, 2013.

Hetenyi, G., Molinari, I., Clinton, J., and Kissling, E.: The AlpArray Seismic Network: current status and next steps, Geophysical Research Abstracts, EGU General Assembly 2016, 18, EGU201611744-1, 2016.

Kissling, E.: Alpine Post-Collisional Orogeny: topics of debate and possible targets for AlpArray research, Geophysical Research Abstracts, EGU General Assembly 2016, 18, EGU2016-2896, 2016.

Krischer, L., Megies, T., Barsch, R., Beyreuther, M., Lecocq, T., Caudron, C., and Wassermann, J.: ObsPy: a bridge for seismology into the scientific Python ecosystem, Computational Science \& Discovery, 8, 014003, doi:10.1088/1749-4699/8/1/014003, 2015.

McNamara, D. E. and Buland, R. P.: Ambient noise levels in the continental United States, B. Seismol. Soc. Am., 94, 1517-1527, doi:10.1785/012003001, 2004.

Peterson, J.: Observations and modeling of seismic background noise, uSGS Open-File report 93-322, 1993.

Stepanek, J. and Claypool, D. W.: GPS signal reception under snow cover: A pilot study establishing the potential usefulness of GPS in avalanche search and rescue operations, Wild. Environ. Med., 8, 101-104, doi:10.1580/10806032(1997)008[0101:GSRUSC]2.3.CO;2, 1997.

Wolin, E., van der Lee, S., Bollmann, T. A., Wiens, D. A., Revenaugh, J., Darbyshire, F. A., Frederiksen, A. W., Stein, S., and Wysession, M. E.: Seasonal and Diurnal Variations in LongPeriod Noise at SPREE Stations: The Influence of Soil Characteristics on Shallow Stations Performance, B. Seismol. Soc. Am., 105, 2433-2452, doi:10.1785/0120150046, 2015. 